ConNotas. Revista de Crítica y teoría literarias / Vol. VI, Núm. 10 / 2008

\title{
Mentir y crear. Aproximaciones a Felisberto Hernández y Juan Carlos Onetti
}

\author{
Jorge TÉLlez VARGAS*
}

\section{Resumen:}

La relación entre la mentira y la ficción es un motivo arraigado en la literatura hispanoamericana del siglo XX. En el caso de Felisberto Hernández y Juan Carlos Onetti cobra una importancia fundamental en la medida en que nos remite a un segundo plano diegético de varios de sus textos. En los cuentos que analizo, "La envenenada" (1931) de Felisberto Hernández y "Un sueño realizado" (1941) de Juan Carlos Onetti, la relación ver$\mathrm{dad} /$ mentira se expresa por medio de imágenes dramáticas puestas en escena que bien podrían entenderse como la poética misma de los textos. En ambos escritores, el desdoblamiento diegético puede verse como el ejercicio de un derecho imprescindible de todo narrador: la creación paralela de mundos que van en busca de la libertad artística. El interés primordial de este artículo se enfoca en el estudio y análisis de los mecanismos que permiten tales desdoblamientos y en la relación que, de esa manera, se establece entre las poéticas de ambos escritores.

\section{Palabras clave:}

Literatura rioplatense, cuento hispanoamericano, puesta en escena, representación, desdoblamiento.

Cuando nuestra civilización occidental comenzó a hablar metódicamente del arte de la palabra, uno de los primeros temas fue el de 
la mentira y su relación con la creación artística. Es ya lugar común notar que Platón decidió expulsar a los poetas de su república por falsos y dañinos a la moral común. El argumento no era descabellado: los poetas, para él, no imitaban la idea de realidad, sino su representación, situación que correspondía a una mentira en tercer grado. La mímesis, en su génesis, es un concepto moralmente cuestionable (véase Platón). Por fortuna, apareció después Aristóteles con una gran lección: la literatura hay que juzgarla desde criterios estéticos, no morales. Los estudios modernos tienen en nuestros días, con todo y algunas desviaciones, el criterio estético como punto de partida para toda apreciación artística.

Hoy sabemos que acercarnos la literatura como quien se acerca a verificar una hipótesis científica implica mutilar el texto. Para decirlo con palabras de Ricardo Piglia: "La ficción trabaja con la verdad para construir un discurso que no es ni verdadero ni falso. Que no pretende ser ni verdadero ni falso. Y en ese matiz indecidible entre la verdad y la falsedad se juega todo el efecto de la ficción" (13). ¿A santo de qué, entonces, hablar de "mentir y crear" como lo propongo en el título? Hablaré, sobre todo, de dos cuentos: "La envenenada" (1931), de Felisberto Hernández, y "Un sueño realizado" (1941), de Juan Carlos Onetti, en los cuales encuentro el binomio mentira/ficción como una suerte de propuesta literaria, de poética.

La mentira aparece en estos cuentos no como resultado de la escritura, como lo veía Platón, sino como motivo estructurante de las narraciones, como uno de los objetos de representación. A nivel estructural, la relación mentira/ficción es primordial en la medida en que, al interior del texto, desdobla los planos diegéticos. Muy fácilmente lo explica Fernando Aínsa en el caso de Onetti, al proponer dos conceptos clave para la lectura del uruguayo: lo "real novelesco" y lo "real imaginario". Es decir, entender lo real novelesco como la diégesis, como los hechos que suceden a lo largo de acontecimientos y episodios; mientras que lo "real imaginario" es un desplazamiento o desdoblamiento al interior de esa diégesis: sueños, deseos, proyecciones que se viven plenamente por los personajes (véase Aínsa). El mejor ejemplo de esto es la creación del 
pueblo de Santa María en La vida breve; lo que allí presenciamos, como realidad novelesca, es la frustración familiar, laboral, económica de Brausén, al mismo tiempo que, dentro de la realidad imaginaria, la ciudad poco a poco comienza a tomar forma. Lo que el lector observa es al protagonista en su cama, triste, cansado, pero poco a poco esa realidad se desdobla y los cimientos de Santa María comienzan a aparecer.

Éste, sin embargo, no es un caso aislado o, al menos, es lo que intento mostrar en este trabajo. La aparición de lo real imaginario -entendido como una ensoñación, como una vivencia paralela a la realidad novelesca- es un motivo constante en la literatura moderna desde el Quijote que, sin embargo, se presenta de manera sistemática en literatura de las primeras décadas del siglo XX en Uruguay y Argentina. En los dos casos que hoy me ocupan, estos desdoblamientos de la realidad toman cuerpo con base en mecanismos dramáticos. Tanto Felisberto como Onetti harán que sus personajes mientan para desdoblar la realidad novelesca. Faltaría matizar que la relación entre mentira y ficción que observo es indisoluble: la mentira ficcionalizada o la ficciónalización de la mentira hermanan a ambos escritores gracias a una coincidencia: la visión de la vida y, por lo tanto, si continuamos con los binomios, de la muerte, como un espectáculo, como una puesta en escena que debe o puede representarse; y la indisoluble relación entre la imaginación y la realización de las acciones, es decir, eso que Aínsa llama lo real imaginario no sólo como materia novelable sino como materia de lo posible. Ambos motivos están estrechamente ligados a la mentira aunque de formas, ya lo veremos, distintas.

¿Qué hilo conductor elegir si el tratamiento, si la ficcionalización es diferente en cada caso? La lectura que propongo encuentra su eje en la relación que en cada texto establece la mentira con "los otros", pues aceptando el hecho de que el acto de mentir implica un discurso velado, un disfraz de la verdad, este acto está siempre enfocado hacia quien lo recibe, aunque éste sea uno mismo. 


\section{La mentira imposible}

La mentira en relación con la idea de la vida como espectáculo, de la imaginación como realización está presente en el cuento "La envenenada” de Felisberto Hernández. El tema del espectáculo en Felisberto no es de ninguna manera un hallazgo; Italo Calvino, por ejemplo, observó muy bien que

sus relatos más típicos son aquellos que gravitan sobre una complicada puesta en escena, sobre un ritual espectacular que se desarrolla en el secreto de un extraño espacio: un patio inundado sobre el que flotan bujías encendidas; un pequeño teatro de muñecas tan grandes como mujeres, colocadas en posiciones enigmáticas; una galería oscura en donde se debe reconocer al tacto objetos que provocan asociaciones de imágenes y de pensamientos. (4)

La cita se refiere a tres cuentos, "La casa inundada", "Las hortensias" y "Menos Julia", textos, en efecto, paradigmáticos con respecto a la puesta en escena. Creo, sin embargo, que ya desde las primeras invenciones el tema de la mentira y de su consecuente puesta en escena está figurado. En el caso que nos ocupa, un escritor, protagonista de la historia, se encuentra ensimismado y angustiado por la falta de tema: "el día era lindo, pero igual a muchos días lindos" o "El paraje era pintoresco como otros lugares pintorescos y nada más" (Hernández, "La envenenada" 69-72). La escritura aparece como la actividad privilegiada para ver en el mundo eso que el ojo normal no ve. Ángel Rama opina que en Felisberto los "ambientes, personajes, asuntos de los cuentos pertenecen mayoritariamente, a la excepcionalidad del mundo, aunque todos, sin dificultad, se asientan en la norma común de ese mismo mundo" ("Su manera" 249-250). La relación entre vida y literatura aparece como indisoluble, pues el escritor piensa: "si quiero asunto tengo que meterme a la vida" (Hernández, "La envenenada" 70). En estas cavilaciones se encuentra cuando tres hombres llegan a su casa para alertarlo sobre el reciente hallazgo de un cadáver en el río: 
Él tenía pensado no ir a esta clase de espectáculos: le producían una cosa, que sintetizando todo lo que hubiera podido escribir sobre esa cosa, le hubiera llamado vulgarmente miedo. Sin embargo, como además de no tener asunto, había leído una poesía que le había llevado a la conclusión de que un hombre podía reaccionar y triunfar sobre sí mismo, entonces decidió aprovechar la invitación que le hicieron los tres hombres y el espectáculo de la envenenada. (70)

De inmediato, el texto propone la concepción de la vida -o en este caso de la muerte- como un espectáculo que, más adelante, se convertirá en la mente del escritor en una escena dramática. Sin embargo, antes de llegar al lugar, el escritor cuestiona su papel dentro de la escena:

En el cerebro de los cuatro hombres había una misma idea: en tres, la curiosidad por el gesto de la cara del literato, y en el literato la preocupación de lo que haría con su cara. Si se abandonaba a la espontaneidad, tal vez pusiera una cara inexpresiva e idiota y, además, no podría abandonarse a su espontaneidad porque sabía que lo observaban; tal vez no podría ser espontáneo ni consigo mismo, porque aunque no hubiera nadie, él mismo sería su observador, tendría la tensión de espíritu del analítico y por más fuerte que fuera el espectáculo, su espíritu oscilaría entre la impresión que le produciría y la impresión que él quería tomar de sí mismo. Entonces se encontró con que no podía ni sabía sorprenderse y, entonces tenía que inventar un gesto interesante. Ni aun esto podía pensar tranquilamente porque sus compañeros le iban dando los datos que conocían de la envenenada y él tenía que escucharlos y comentarlos. Para eso inventó un gesto y un comentario que le sirvió para abandonarse a pensar en todo lo que se le antojaba, para dejar sus pensamientos libres cual una cosa libre; puso su cara hacia el frente, pero no para mirar lo que tenía adelante, sino hacia lo que los literatos habían definido como lo infinito, lo desconocido, etcétera. El comentario fue el silencio. (Hernández, "La envenenada” 70-71) 
El escritor debe mentir para que su papel sea verosímil; enfrentado a la colectividad que representan los tres hombres, él se encuentra al margen; el lugar excéntrico que le confiere la calidad de "literato" lo obliga a representar un papel que lo hace identificable y consecuente para los demás. El escritor representará, a partir de ese momento, dos papeles: el de juez de la escena, con respecto a "los otros", y el de soñador, pues debe convertir la muerte de la envenenada en arte, en ficción, tarea que hará aparecer el espacio de lo real imaginario como un lugar de ensoñación. Para sobrellevar este ir y venir entre ambos mundos cuya relación es significativa en el cuento, el mundo de lo real novelesco y lo real imaginario, el escritor echa mano de la mentira y la representación.

La mentira funciona como un mecanismo de autoafirmación: ser (escritor) para los otros. Por esa necesidad las cavilaciones van y vienen de lo real novelesco a lo real imaginario, con sus toques de dramatismo: ${ }^{1}$

Aquí los pensamientos del literato se prendieron hambrientos de este detalle, y ya le pareció que hacía un cuento y que decía que ella [la envenenada] había ido más lejos de lo que la imaginación de la gente suponía: había ido donde los literatos habían definido como lo infinito, lo desconocido, etc. De pronto los pensamientos se le detuvieron y se fijó que los dos hombres que callaban habían quedado algunos pasos atrás y ahora conversaban; entonces sus pensamientos le volvieron a atacar y se imaginó que, al ellos caminar de dos en dos, llevaban un ataúd. También se dio cuenta, analizando su propio yo, que este último pensamiento decoraba muy bien el espectáculo que dentro de poco verían. (Hernández, "La envenenada" 71)

Creo que la cosificación (véase Rama) que tan persistente como atinadamente ve la crítica en la obra de Felisberto tiene que ver en

\footnotetext{
${ }^{1}$ Uso el término "dramatismo" en su sentido teatral.
} 
este cuento con la relación del personaje con ambos mundos. Cada uno de los objetos que ve, e incluso las partes de su cuerpo y sus pensamientos, tienen que sortear el trayecto entre la vida, o la realidad, y la ficción. Entre la visión de la muerte como un espectáculo y la necesidad de metaforizar esa realidad, el escritor necesita caracterizarse también como tal, como el puente entre lo verificable y lo ficcionalizado:

Durante mucho rato el literato quiso suponerse que estaba acostumbrado a espectáculos como aquél y quiso empezar a construir su cuento [...], pero los ojos se le habían quedado muy abiertos y fijos [...]; ya había corrido por allí la noticia de que era escritor, y la gente pensaría que tal vez él y no el juez, estaría más cerca del misterio de aquella muerte [...]; cuando los compañeros lo vieron moverse, les pareció que era algo así como una gran máquina moderna del pensamiento, y que al moverse era porque ya tenía la solución [...]; entonces, uno de ellos, el antiguo admirador, lo interrogó [...], pero el literato tuvo pronto el juicio, el elogio, o la solución antes que viniera el juez: seguiría con el silencio: esta nueva solución, que era igual a la de antes de ver a la envenenada, le había surgido al recordar cómo otros literatos habían triunfado con el sencillo procedimiento de insistir: él insistiría en su silencio; tal vez cuando los compañeros le acompañaran hasta su casa, él no les diría ni buenas tardes, y esa descortesía en aquel momento, haría crecer en el ánimo de los demás, el concepto que de él tendrían. (Hernández, "La envenenada" 74-75)

La mentira se dirige hacia sí misma. Que el personaje se mienta, en la medida en que construye todo un escenario alrededor de la envenenada, tiene que ver con su posicionamiento frente al mundo y el cuento refleja eso: la historia de un hombre que busca insertarse en un espacio social, el literario en este caso, y su imposibilidad para hacerlo debido a la terrible relación entre vida y arte. Para el escritor, la vida no basta, y en el arte, en el proceso de la ficción es posible que el hombre se pierda, como lo observa Enriqueta Morillas: 
No solamente nos comunicará su necesidad de distraerse en aras de la ensoñación [...] Va a participarnos, abriéndonos bruscamente las puertas del reino de lo imaginario, lo que ocurre en la antesala, compleja y difícilmente ordenable, de la producción de la escritura. (272)

Por eso la necesidad de metaforizar la escena y por eso la necesidad de verla desde "otro ángulo":

El espectáculo era demasiado fuerte para el literato; en el cuerpo de la envenenada había cosas extrañas, contradictorias y también irónicas: los pies estaban cruzados, y había en ellos la tranquilidad de la persona que se ha acostado a dormir la siesta y el cuerpo disfruta de la frescura del césped y de la placidez del sueño; pero sin embargo, el cuerpo de la envenenada estaba arqueado, tenía por punto de apoyo un talón y los hombros, y todo el busto demasiado echado hacia adelante; la cabeza estaba doblada y su posición hacía pensar en lo mismo de los pies, pero la cara estaba muy descompuesta y los músculos en tensión; un brazo lo tenía para arriba, rodeaba la cabeza como un marco y la posición era tan tranquila como la cabeza y los pies; pero el puño estaba muy apretado. Lo más terrible, la protesta más desesperante que había en la envenenada, estaba en el otro brazo, el que no le servía de marco a la cabeza: estaba muy separado del cuerpo, y desde el codo hasta el puño había quedado parado como un pararrayo; el puño no estaba cerrado del todo, y de en-tre los dedos que estaban crispados y juntos, salía un pañuelito que flameaba con la brisa. Cerca del cuerpo estaba el vaso y el papel. (Hernández, "La envenenada" 72-73)

Este montaje está descrito desde su propia óptica, desde la visión del final de un pleito amoroso como una puesta en escena. Desde ese otro ángulo, el narrador-personaje nos muestra una escena que nadie más que él ve. La crítica ha tomado estos procedimientos como mecanismos para volver inverosímiles las anécdotas, como un 
juego específico de Hernández que consiste en burlar las ideas, sentimientos o cosas de la realidad que aceptamos como las verdaderas con otros que también son de la realidad pero que nos sorprenderán como lo que llamamos "inverosímiles". Y este campo, el de los “inverosímiles" será el predilecto del narrador uruguayo. (Rama, "Su manera” 249)

Lo observa también Enriqueta Morillas:

Impugnado de manera explícita o tácita lo que desde una óptica racionalista es tenido por real o verdadero, su mayor empeño consistirá en inverosimilizar el universo narrado [...] Los objetos tendrán alma o espíritu, los seres aparecen representados en sus facetas no utilitarias. ${ }^{2}$ (265)

En esto consiste la otra visión del narrador y en esto consiste su lucha. La relación vida/arte termina por convertirse en la relación natural/artificial: "esta vez la muerte tenía una vida especial que no había en la muerta de cera; entonces haría resaltar el valor de las cosas naturales sobre las artificiales" (Hernández, "La envenenada" 76).

El narrador finalmente no puede mentirse y la artificialidad de la escena que imaginó y que él mismo representaba termina por supeditarse a la muerte "real": "Claro está, que enseguida diría que lo más impresionante era que no había tal clase [de drama], y que aquello era una espantosa realidad para la protagonista" (76). El protagonista termina sin tema y en su casa hundido en cavilaciones debido a su imposibilidad por comprender para qué le han servido éstas:

${ }^{2}$ Quizá debido a esta percepción tan bien apuntada de lo "inverosímil" se deba la percepción en lectores y críticos que le adjudica un carácter fantástico a Felisberto. La afirmación ha sido bien rebatida por Rafael Olea Franco en su artículo "Felisberto Hernández: Una literatura inasible“. Ya Julio Cortázar, en 1975, cuestionaba esta actitud: "Releyendo a Felisberto he llegado al punto máximo de este rechazo de la etiqueta 'fantástica'; nadie como él para disolverla en un increíble enriquecimiento de la realidad total, que no sólo contiene lo verificable sino que lo apuntala en el lomo del misterio como el elefante apuntala al mundo en la cosmogonía hindú" (7). 
Él se diferenciaba de los demás literatos, en que ellos ignoraban los misterios y las casualidades de la vida y la muerte, pero se empecinaban en averiguarlo; en cambio para él no significaba nada haber sabido el por qué (sic) de esos misterios y casualidades, si con eso no se evitaba la muerte. (79)

En una curiosa resolución, lo real novelesco termina por vencer a lo real imaginario, a la representación, a los sueños, a las estrategias de visión del escritor para quien la realidad se impone siempre sobre la ficción. La mentira no puede llegar más allá de la imaginación pues, en este caso, la posibilidad de realización se cancela sin que ello implique negar el proceso de construcción dramático-imaginario. Este tipo de desenlaces son característicos de la narrativa de Felisberto, como lo explica Rafael Olea Franco:

Como sus relatos no se dirigen nunca hacia una conclusión de asombro, no es infrecuente que algunos lectores sientan que el texto termina de forma abrupta. Esto no debe entenderse, empero, como una deficiencia, sino más bien como la propuesta de una nueva estética, basada en la intención deliberada de no construir un desenlace argumental, el cual destruiría la estructura interna de la obra; para decirlo de un modo clásico, si Felisberto hubiera rematado sus textos con un fin argumental, esa decisión no sería más que un fallido recurso deux ex machina, o sea, un elemento ajeno a la coherencia interna de la obra. (147)

Con "La envenenada" Felisberto parece llevar al grado extremo la negación de final argumental, pues su personaje se lo niega también a sí mismo al no escribir su cuento. ¿Hasta dónde podríamos pensar que nuestro escritor-personaje logró vencer, muchos años después, su conflicto y encontrar el tema que buscaba? Y una vez encontrado escribió un relato llamado "Las hortensias", en el cual uno de sus personajes explica la fascinación por las "escenas":

Cuando miro una escena [muñecas en vitrinas cuya situación varía periódicamente] me parece que descubro un recuerdo 
que ha tenido una mujer en un momento importante de su vida; es algo así - perdonen la manera de decirlo- como si le abriera una rendija en la cabeza. Entonces me quedo con ese recuerdo como si le robara una prenda íntima; con ella imagino y deduzco muchas cosas y hasta podría decir que al revisarla tengo la impresión de violar algo sagrado; además, me parece que ése es un recuerdo que ha quedado en una persona muerta; yo tengo la ilusión de extraerlo de un cadáver; y hasta espero que el recuerdo se mueva un poco. (Hernández, "Las hortensias" 197-198)

Me parece que la relación entre las obras es innegable y que bien puede interpretarse este pasaje, y el cuento mismo, como un nuevo intento por escribir (o por ver o por escenificar) aquel recuerdo de la envenenada. El intento, en esta ocasión, es notoriamente satisfactorio.

\section{La mentira realizada}

Diez años después, Juan Carlos Onetti escribió “Un sueño realizado", en el cual encontramos también la vida unida al arte, en este caso el teatro, y el tratamiento de la imaginación como medio para realizar las acciones. En el cuento, la concepción teatral de la vida -o por mejor decir, de la muerte- se propone explícitamente: con los personajes de Onetti - a diferencia del escritor Felisberto- no es necesario hablar metafóricamente de la puesta en escena porque en el cuento se desarrolla la producción de una; ${ }^{3}$ más que aceptada está la idea de que

${ }^{3}$ En su discurso de ingreso a la Academia Mexicana de la Lengua, Celestino Gorostiza habla sobre la mentira teatral: "Lo teatral es por antonomasia la imagen de la afectación, de la falsedad, de la mentira, de la simulación. Y no podría ser de otra manera, puesto que todo en el teatro tiende a engañar a los sentidos y al entendimiento [...]; y sin embrago, con todo este fárrago de espejismos el teatro debe crear la ilusión de una verdad alucinante, no sólo durante el breve lapso de la representación, 
Uno de los conceptos esenciales de la novelística de Onetti: el juego, la farsa, la mentira, la comedia sin fin, noción que se bosqueja en sus lejanos primeros cuentos y, treinta años después, se convierte en el motivo estructurador de El astillero. (Verani 116) (véase Moreno Aliste)

El caso de Onetti concilia más que ninguno de los otros dos el sueño con su realización aunque, como veremos, pone en crisis el significado de ésta. Creo que esta es una de las características de la obra de Onetti y concuerdo con Fernando Curiel, uno de sus grandes lectores, cuando escribe que "Sin lugar a dudas, uno de los documentos constitutivos del universo narrativo que nos ocupa denomínase Un sueño realizado" (162).

Una mujer cuya identidad no conocemos llega con Langman, empresario teatral, para proponerle una obra,

un momento, una escena, se puede decir, y allí no pasa nada, como si nosotros representáramos esta escena en el comedor y yo me fuera y ya no pasara nada más [...]; no es cuestión de argumento, hay algunas personas en una calle y las casas y dos automóviles que pasan. Allí estoy yo y un hombre y una mujer cualquiera que sale de un negocio de enfrente y le da un vaso de cerveza. No hay más personas, nosotros tres. El hombre cruza la calle hasta donde sale la mujer de su puerta con la jarra de cerveza y después vuelve a cruzar y se sienta junto a la misma mesa, cerca de mí, donde estaba al principio. (Onetti, "Un sueño" 107-108)

El empresario busca a su actor, Blanes, quien inmediatamente le reprocha la mentira y la inverosimilitud del caso; "no es mentira

sino para todos los tiempos venideros [...]; se hace evidente así la paradoja fundamental del teatro, la que constituye su esencia misma y de la que arrancan todas las otras: el teatro es una mentira destinada a convertirse en la única verdad, en la única imagen verdadera de una época, de una sociedad, de una nación” (22-23). 
mía”, contesta el productor, como para retar al lector a encontrar al personaje que miente. La narración del sueño, de la obra de teatro llamada Un sueño realizado se repite tres veces: la primera que cité arriba, una segunda vez en la cual la mujer lo narra con más detalles frente al empresario y Blanes, y la tercera en el momento de la representación, hecho en principio intrascendente cuya relevancia podría aumentar si se le compara con las tres veces en que la mujer nombra su obra. A la pregunta de Langman sobre cómo se llama ésta, ella contesta: "El sueño, El sueño realizado. Un sueño realizado" (106). Aunque me considero enemigo de la interpretación literaria basada en la numerología, no puedo dejar pasar la relación que hay entre las veces que se enuncia el sueño y los tres nombres que da la mujer. El primero, ya lo vimos, es un argumento frugal que se basa en desplazamientos mecanizados de los personajes. El segundo es mucho más detallista:

En la escena hay casas y aceras, pero todo confuso, como si se tratara de una ciudad y hubieran amontonado todo eso para dar una impresión de una gran ciudad. Yo salgo, la mujer que voy a representar yo sale de una casa y se sienta en el cordón de la acera, junto a una mesa verde. Junto a la mesa está sentado un hombre en un banco de cocina. Ése es el personaje suyo. Tiene puesta una tricota y gorra. En la acera de enfrente hay una verdulería con cajones de tomate en la puerta. Entonces aparece un automóvil que cruza la escena y el hombre, usted, se levante para atravesar la calle y yo me asusto pensando que el coche lo atropella. Pero usted pasa antes que el vehículo y llega a la acera de enfrente en el momento que sale una mujer vestida con traje de paseo y un vaso de cerveza en la mano. Usted lo toma de un trago y vuelve en seguida que pasa un automóvil, ahora de abajo para arriba, a toda velocidad; y usted vuelve a pasar con el tiempo justo y se sienta en el banco de cocina. Entretanto yo estoy acostada en la acera, como si fuera una chica. Y usted se inclina un poco para acariciarme la cabeza. (111) 
A los mecanizados movimientos de la primera versión se le agregan comentarios que caracterizan a los personajes (el miedo, la actitud de "ser como una chica") y que enfatizan la descripción de la escenografía (casas, aceras, banco de cocina, autos). Pero lo más importante es la concepción del actor como otra persona: "la mujer que voy a representar yo sale"; "Junto a la mesa está sentado un hombre en un banco de cocina. Ése es el personaje suyo". Hay, más claramente que en el primero, una concepción teatral, pues en aquél, más simple, la explicación comienza con "como si nosotros representáramos esta escena”. En esta versión los personajes del cuento dejan de ser ellos mismos y se convierten en otros personajes, los de la obra de teatro. Finalmente y por voz de Langman, que se esconde por sentirse ajeno a la representación, nos enteramos de cómo se desarrolló la escena:

Vi cómo ella salía de la puerta de la casucha, moviendo el cuerpo como una muchacha -el pelo, espeso y casi gris, suelto a la espalda- daba unos largos pasos que eran, sin duda, de la muchacha que acababa de preparar la mesa y se asoma un momento a la calle para ver caer la tarde y estarse quieta sin pensar en nada; vi cómo se sentaba cerca del banco de Blanes y sostenía la cabeza con una mano, afirmando el codo en las rodillas, dejando descansar las yemas sobre los labios entreabiertos y la cara vuelta hacia un sitio lejano que estaba más allá de mí mismo, más allá también de la pared que yo tenía a la espalda. Vi cómo Blanes se levantaba para cruzar la calle y lo hacía matemáticamente antes que el automóvil que pasó echando humo con su capota alta y desapareció en seguida. Vi cómo el brazo de Blanes y el de la mujer que vivía en la casa de enfrente se unían por medio de la jarrita de cerveza y cómo el hombre bebía de un trago y dejaba el recipiente en la mano de la mujer que se hundía nuevamente, lenta y sin ruido, en su portal. Vi, otra vez, al hombre de la tricota azul cruzar la calle un instante antes de que pasara un rápido automóvil de capota baja que terminó su carrera junto a mí, apagando en seguida su motor, $y$, mientras se desgarraba el 
humo azuloso de la máquina, divisé a la muchacha del cordón de la acera que bostezaba y terminaba por echarse a lo largo en las baldosas, la cabeza sobre un brazo que escondía el pelo, y una pierna encogida. El hombre de la tricota y la gorra se inclinó entonces y acarició la cabeza de la muchacha, comenzó a acariciarla y la mano iba y venía, se enredaba en el pelo, estiraba la palma por la frente, apretaba la cinta clara del peinado, volvía a repetir sus caricias. (115-116)

La representación, como arte espectacular, es evidentemente más rica que la narración del sueño, que podríamos interpretar como el libreto. Durante la representación, los personajes (Blanes, su amiga y la mujer) dejan de ser ellos para convertirse en "el hombre de la tricota", "la mujer que vivía en la casa de enfrente" y "la muchacha del cordón". Obra de teatro sui generis que se compone de una sola escena y en la que el dramatis personae se compone no de nombres sino de características que acompañan a los personajes. Lo que importa, en todo caso, es que en el escenario todos ellos encarnan otro papel, sea de personajes teatrales o, en el caso de Langman, de espectador. ${ }^{4}$

Para Corinne Enaudeau,

el teatro concentra en el escenario la paradoja de la representación. Representar es sustituir a un ausente, darle presencia y confirmar la ausencia [...]; la representación sólo se presenta a sí misma, se presenta representando a la cosa, la eclipsa y la suplanta, duplica su ausencia. (27)

${ }^{4}$ Para David Lagmanovich, "La mujer del relato no desea simplemente volver a presenciar la escena sugerida por el sueño que al parecer ha tenido en una época anterior, ya alejada de la acción cuentística: lo que quiere es realizar esa experiencia, objetivarla, volver a vivirla [...] Su proyecto implica pasar de la irrealidad del sueño a la irrealidad del teatro, obviando la intervención de la vida real: para esto necesita del empresario Lagman, quien en virtud de su profesión tiene la posibilidad de combinar lo necesario para satisfacer sus deseos" (210). 
¿Cómo funciona esta representación? ¿Hacía quién está dirigido Un sueño realizado? No es sino hasta su representación cuando la escena de la mujer gana su nombre: se cambia el artículo determinado 'el' por el indeterminado 'un', lo que ayuda a cubrir de misterio el sustantivo que le sigue y la representación. El enigma a resolver es: ¿de qué sueño se habla?, ¿̇en qué consiste?

El enigma se plantea al final de la obra:

Algo extraño estaba sucediendo a mi derecha, donde estaban los otros, y cuando quise pensar en eso tropecé con Blanes que se había quitado la gorra y tenía un olor desagradable a bebida y me dio una trompada en las costillas, gritando: $-\mathrm{No}_{0}$ se da cuenta que está muerta, pedazo de bestia. (Onetti, "Un sueño" 117)

La interpretación de este final sólo puede pensarse desde la perspectiva de la mujer, puesto que los otros personajes no saben nada más: 5

La mujer aparece encarnando el paradigma de ese gran juego de la representación, al que, además, le da una significativa vuelta de tuerca, puesto que a la indistinción entre personaje y persona, entre el papel y la existencia, que la convierte en un signo de representación en la representación, entregada a la luz pública sin preservar el secreto de la interioridad de

${ }^{5} \mathrm{Ni}$ siquiera Blanes, quien convive más que todos con la mujer, logra desentrañar el misterio: "Yo le pregunté qué era esto que íbamos a representar y entonces supe que estaba loca. ¿Le interesa saber? Todo es un sueño que tuvo, ¿entiende? Pero la mayor locura está en que ella dice que ese sueño no tienen ningún significado para ella, que no conoce al hombre que estaba sentado en tricota azul, ni a la mujer de la jarra, ni vivió tampoco en un acalle parecida. ¿Y por qué, entonces? Dice que mientras dormía y soñaba eso era feliz, pero no es feliz la palabra sino otra clase de cosa. Así que quiere verlo todo nuevamente. $Y$ aunque es una locura tiene su cosa razonable. Y también me gusta que no haya ninguna vulgaridad de amor en todo esto" (Onetti, "Un sueño" 114). 
aquello más íntimo, su sueño, agrega su condición de autora del guión teatral que lo repone. (Ferro 115)

Ella es quien logra realizar su ensoñación y quien posibilita afirmar que la imaginación es casi equivalente a la realización de las acciones. Pero al no comunicar nada más sobre sus motivos, su muerte puede leerse de dos maneras. ${ }^{6}$ La primera, que al final de su sueño ella muere efectivamente, de ahí que el final de la representación coincida con su fallecimiento, que, un paso más allá de la lectura, podría considerarse suicidio. La segunda, que el plano de la ficción, del drama, supera la "realidad novelesca" y entonces la mujer finge su muerte como parte de la representación; en esta lectura, Blanes puede ser sorprendido por la muerte simulada o estar en acuerdo con la mujer, aunque siempre la idea de la muerte en el escenario equivaldría a la muerte en la vida "real".

Cualquiera de los dos casos nos instala en el campo de la mentira que, en este caso, se construye por omisión. La mujer nunca dice qué busca con la representación ni qué significa para ella. Por eso

${ }^{6}$ Es evidente que todo lo que se diga al respecto entrará directamente en el terreno de la especulación, pues no hay hechos textuales que nos ayuden a dilucidar el misterio. Sin embargo, en dicho terreno también hay grados, por lo que transcribo dos buenas lecturas que, si bien no terminan por resolver el enigma, dan elementos para llegar a ello. La primera es de David Lagmanovich, quien opina que "El sueño, la irrealidad del sueño, aparentemente se ha realizado; pero la irrealidad del sueño instaura la realidad de la muerte. El final de la buscada representación coincide -para sorpresa de los personajes, y quizá también del lector-con la pacífica muerte de la mujer [...]; una primera aproximación al cuento podría ser la de comprenderlo como una suerte de mecanismo de desrealización (todo lo contrario de lo que -irónicamente-apunta el título) [...] En esta realidad desagradable aparece una mujer que, ya a partir de su aspecto sugestivamente anacrónico, implica un distanciamiento de esa realidad, un cambio hacia la dirección contraria" (211). La segunda es de Fernando Curiel, para quien "La autora habíale confiado [a Blanes] que la escena era la materia de un sueño que la inundaba de felicidad pero cuyo significado se le escapaba. Para descifrarlo lo representaría. La realidad, así fuera una realidad artificiosa, pasaba a ocupar el rol de un instrumento, esta vez no de tortura, sino de revelación. La puesta en escena, ella y sólo ella lo sabe, es un conjuro" (168-169). 
nadie sabe, ni siquiera el lector, cómo interpretar el resultado. La representación del sueño de la mujer carece, en apariencia, de motivación. Pareciera que su público se constituiría sólo por ella, pues sólo ella tendría la posibilidad de entenderlo. Que Langman sea el espectador es equiparable a su calidad de narrador del cuento. ${ }^{7}$

\section{Conclusión}

La mentira de la mujer del cuento de Onetti no puede entenderse tan explícitamente como la mentira del escritor protagonista del cuento de Felisberto (que necesita afirmarse como tal). En los dos casos habría que diferenciar la explícita puesta en escena (la muerte de la envenenada, la muerte de la mujer) con sus motivaciones, siempre sustentadas con base en la mentira. Para ello, es necesario recordar que la imaginación, la ensoñación, está indisolublemente ligada con la realización de los actos (aunque en el caso del escritor, se elija no ejecutarla), cuya consecuencia lógica es la concepción de la realidad como una puesta en escena. José Pedro Díaz observa bien la sintomática presencia del espectáculo en Onetti y Felisberto y concluye que con ella "[se pone de manifiesto] un notorio rechazo por el mundo real y concreto, un deseo infructuoso de realizar lo imaginario, y un movimiento de regresión que busca refugiarse en el pasado, en el recuerdo, y en las imágenes que lo pueblan" (37-38). A semejante conclusión llega Rose Corral al analizar la relación de Onetti con la obra de Roberto Arlt:

Un motivo clave, tanto en la obra de Arlt en general (incluido el teatro) como en la de Onetti, desempeña aquí, en ambas

7 “'La voz de Langman - dice Roberto Ferro- está surcada por la presencia de un fantasma doble, por una parte, su relato retoma y repite el guión-libreto de la mujer que anticipa la representación como una suerte de prólogo, de afuera de la obra y, por otra, narra lo que vio en el mimodrama; por lo tanto, la estructura del cuento se funda en un simulacro como copia de la copia” (119). 
novelas [Los siete locos/Los lanzallamas y El astillero], un papel central: el recurso a la farsa, la mentira, la simulación, porque se ha perdido la capacidad de una interacción directa y eficaz con la realidad. Ante un mundo desolador y sin alternativas, es necesario inventarse ficciones, utopías, y construir con ellas un precario refugio. (259)

La permanente oscilación entre lo real novelesco y lo real imaginario que hay en los dos textos funciona, a la vez, como escape y enfrentamiento a una realidad que busca modificarse artísticamente (como con el escritor de Felisberto) o que busca revivirse (como en el caso de la mujer de Onetti, aunque sus fines estén velados).

Por supuesto que, al igual que semejanzas, entre los dos autores existen divergencias. El tiempo en el que cada uno escribe sería suficiente para considerarlos por separado; los diez años que separan la redacción de "Un sueño realizado" y la "Envenenada" se multiplican si consideramos ese momento como una época de grandes cambios debido a la rápida modernización de América del Sur. Sin embargo, he intentado mostrar que el motivo de la mentira y sus consecuencias dramáticas hermanan la escritura de estos dos escritores.

El motivo de la mentira, por lo demás, sigue vigente y reclama un estudio que lo contemple en el desarrollo de la literatura rioplatense. Este motivo llega al extremo en la década de los noventa con la publicación de La ciudad ausente (1992), de Ricardo Piglia, novela en la que todo lo que viven los personajes está fraguado por una máquina de historias. Me parece digno de tomarse en cuenta que, a final de siglo, la literatura haya optado por suprimir casi al máximo lo real novelesco para mostrarnos, únicamente, el espacio de lo real imaginario, enaltecido y homenajeado con la figura del Museo de la novela de Piglia. 


\section{Bibliografía}

Aínsa, Fernando. "Los posibles de la imaginación." Juan Carlos Onetti. Ed. Hugo J. Verani. Madrid: Taurus, 1987. 115-140.

Calvino, Italo. "Las zarabandas mentales de Felisberto Hernández." Felisberto Hernánder. Novelas y cuentos. Selección, notas, cronología y bibliografía José Pedro Díaz. Caracas: Biblioteca Ayacucho, 1985. 3-5.

Corral, Rose. "Onetti/Arlt o la exploración de algunos vasos comunicantes." Reflexiones lingüisticas y literarias. Vol. II. Literatura. Eds. Rafael Olea Franco y James Valender. México: El Colegio de México, 1992. 251-267.

Cortázar, Julio. "Prólogo.” Felisberto Hernández. La casa inundada y otros cuentos. Barcelona: Lumen, 1975. 5-9.

Curiel, Fernando. Onetti: calculado infortunio. México: Premiá Editora, 1984.

Díaz, José Pedro. El espectáculo imaginario. Juan Carlos Onetti y Felisberto Hernández. ¿Una propuesta generacional? Montevideo: Arca, 1986.

Enaudeau, Corinne. La paradoja de la representación. Tr. Jorge Piatigorsky. Buenos Aires: Paidós, 1998.

Ferro, Roberto. Onetti/La fundación imaginada. La parodia del autor en la saga de Santa María. Buenos Aires: Alción Editora, 2003.

Gorostiza, Celestino. Las paradojas del teatro. México: Talleres Gráficos de la Librería Madero, 1960.

Hernández, Felisberto. Obras completas de Felisberto Hernández, vols. 1-2. México: Siglo XXI, 2000.

Lagmanovich, David. Acotaciones a 'Un sueño realizado'. Juan Carlos Onetti. Ed. Hugo J. Verani. Madrid: Taurus, 1987. 205-216.

Moreno Aliste, Ximena. Origen y sentido de la farsa en la obra de Juan Carlos Onetti. Poitiers: Centre de Recherches Latino-Américaines de l'Université, 1973.

Morillas, Enriqueta. "Las primeras invenciones de Felisberto Hernández.” Escritura 7. 13-14 (1982): 259-279.

Muñoz Molina, Antonio. "Prólogo.” Juan Carlos Onetti. Cuentos completos (1933-1993). 9a ed. Madrid: Alfaguara, 2000. 11-26. 